\title{
A proposed model of dehumanisation and its relevance to dehumanisation in dementia care.
}

\author{
Hana Speering ${ }^{1} \&$ Lara Speering $^{1}$ \\ 1School of Medicine, University of Wollongong, Wollongong, NSW 2522, Australia.
}

\begin{abstract}
The term dehumanisation refers to the ways in which a person is perceived to be less than human or treated as if they are less than human. It involves treating a person as if they are a child or infant, like an animal or non-living object, or as if they are dead, or any other way in which someone fails to be treated like a human being with an adult identity. Dehumanisation is widespread in dementia care; it is a major obstacle to person-centred care and has poor outcomes for people with dementia. This article proposes a new model of dehumanisation. The New Model presents a new way of describing dehumanisation that has been synthesised from current understanding about the phenomenon and reflects what is presently known about the subject. The model aims to summarise existing theories and models of dehumanisation and make dehumanisation theory accessible to students and trainees in healthcare. This article describes the new model, discusses existing models and theories in the literature, and explores the potential role of the new model in solutions for reducing dehumanisation in dementia care.
\end{abstract}

Keywords: Dehumanisation, dementia care, healthcare education, residential aged care facilities, positive dehumanisation, negative dehumanisation.

\section{Introduction}

Dehumanisation has a pervasive presence in healthcare settings, including hospitals, clinics, and aged care facilities to name a few. The term dehumanisation refers to the ways in which a person is perceived to be less than human or treated as if they are less than human (Haslam, 2006; Haslam and Stratemeyer, 2016). It involves treating a person as if they are a child or infant, like an animal or non-living object, or as if they are dead, or any other way in which someone fails to be treated like a human being with an adult identity (Haslam and Loughnan, 2014). Research on dehumanisation has grown significantly in recent years, with areas addressed including racism, policing and criminal justice, politics and international relations, and medicine and healthcare (Haslam and Stratemeyer, 2016). Although healthcare has received significant attention over the last decade, unfortunately dehumanisation has been researched far less in the context of dementia care. This gap in the literature is

Contact: Hana Speering $ه$ hmcs990@uowmail.edu.au 
necessary to address as people with dementia are dehumanised in aged care facilities in many ways. For example, age-inappropriate recreational activities are used in aged care facilities that would be better suited to a five-year-old child than an 80-year-old man or woman (Ryvicker, 2009). Providing care or treatment to a person with dementia without asking for permission or providing an explanation (Speering, Speering and Archer, 2020). Actions such as spooning food into a persons' mouth without warning or asking for permission, or moving furniture around with the person still seated in it, with no verbal acknowledgement given to the person with dementia (Ryvicker, 2009). Excluding the person with dementia from social activities and denying them human interaction are also common examples of dehumanisation in aged care (Brannelly, 2011). Language can dehumanise people with dementia; for example, people with dementia have been described as being "not all there" and "demented" (Swaffer, 2014: 711). Dehumanisation is a critical issue to be addressed as it known to impact health outcomes and reduce the quality of life of the people dehumanised, whereas the implementation of 'humanising' care has been shown to improve the quality of life of people with dementia (Miron et al., 2017; Borbasi et al., 2012).

This paper reviews the existing models and theories of dehumanisation described in the literature and proposes a new model of dehumanisation. The aim of this new model is to summarise dehumanisation theory into one model that is cohesive, widely applicable, and accessible to all types of healthcare staff who may have varying levels of education, training and insight. This model can act as a guide to understanding and identifying dehumanisation in healthcare settings and could serve to reduce dehumanisation when incorporated into training solutions. Having insight into the phenomenon could help healthcare staff work in ways that maintain the personhood of the people they provide care to, and knowing what dehumanisation is and what it looks like could enable dehumanising treatment to be addressed and replaced with more person-centred approaches.

\section{Summary of Background Theory}

Dehumanisation has both cognitive and behavioural components; it describes perceptions and attitudes that are dehumanising as well as behaviours that treat people as less than human (Haslam and Loughnan, 2014). Many causes of dehumanisation have been proposed. Ageism, stigma, discrimination, prejudice, and stereotypes can give rise to dehumanising perceptions of the target person or group (Dionigi, 2015; Haslam, 2006). Researchers in the medical humanities have explored dehumanisation as a strategy unknowingly employed by healthcare workers to protect themselves against the psychological burden of caring for people who are suffering, and they have also considered how practices in healthcare objectify care recipients (Haque and Waytz, 2011; Boddington and Featherstone, 2018). Time constraints have also been cited by aged care staff as justifications for dehumanising treatment (Persson and Wästerfors, 2009; Boddington and Featherstone, 2018). Furthermore, executive thinking, language, perspective-taking, planning, complex emotions, and selfcontrol characterise the human mind and distinguishes people from animals. Because these characteristics are affected in dementia, these changes may influence how people with dementia are perceived and potentially contribute to dehumanising perceptions. The 
different ways in which the cognitive and behavioural symptoms of dementia manifest may give rise to different forms of dehumanisation. Symptoms such as diminished cognitive ability, difficulty communicating and reduced awareness, alongside the use of sedatives, could give rise to the perception that people with dementia lack human responsiveness and are more similar to objects than people (Seaman, 2020; Heap and Wolverson, 2018).

Behaviours like spontaneous singing, humming, tapping, crying, yelling, or hitting could give the impression that the person with dementia is irrational, unreasonable, and lacking in selfcontrol, and consequently engenders the perception that people with dementia are similar to children or animals. Furthermore, the care needs of people with dementia might be likened to those of childlike or infants, and consequently the person with dementia may be perceived to be childlike or infant-like (Seaman, 2020). The stereotypes and stigma surrounding dementia means that a person may have negative perceptions about people with dementia before he or she meets someone with dementia. In this case, the disease presentation of dementia could potentially reinforce dehumanising perceptions already held. More research is needed in this area to establish how the disease presentation of dementia plays a role in dehumanising perceptions.

\section{A New Model}

\section{Overview}

The New Model proposes two forms of dehumanisation: positive dehumanisation and negative dehumanisation, with the term positive referring to factors added and the term negative to factors removed. In positive dehumanisation, the person is perceived or treated as having characteristics that are associated with non-human entities like animals or objects, or characteristics associated with children and infants rather than adults. Conversely, in negative dehumanisation the person is perceived or treated as lacking characteristics that are associated with adult people.

Exploring negative dehumanisation first, figure 1 shows negative dehumanisation as occurring when humanising factors are SUBTRACTED from a persons' perceived identity. These humanising factors constitute the characteristics, values, attributes, or emotions that define as person as a full adult human. To name a few, these factors include values such as privacy, dignity, and autonomy; attributes like sophistication, intelligence, competence, and rationality; and emotions such as hope, joy, love, and pride. Negative dehumanisation involves perceiving or treating a person as if they lack these things and consequently denies the person their adult identity. Denying a person these humanising factors treats the person as if they are less than fully human and is therefore dehumanising.

In contrast, positive dehumanisation occurs when dehumanising factors are ADDED to a persons' perceived identity. These dehumanising factors are the characteristics, values, attributes, or emotions associated with animals, objects, children, infants, or dead people. For example, a person is positively dehumanised when they are viewed as being simple-minded like a child or infant, emotionally inert like an object or dead person, or unintelligent or 
irrational like an animal or infant. A person is positively dehumanised when the dehumaniser likens the person to something that is not a full human adult and consequently denies the person a human adult identity. In both positive and negative dehumanisation, the dehumanised person is ultimately perceived or treated as something that is not human or less than human.
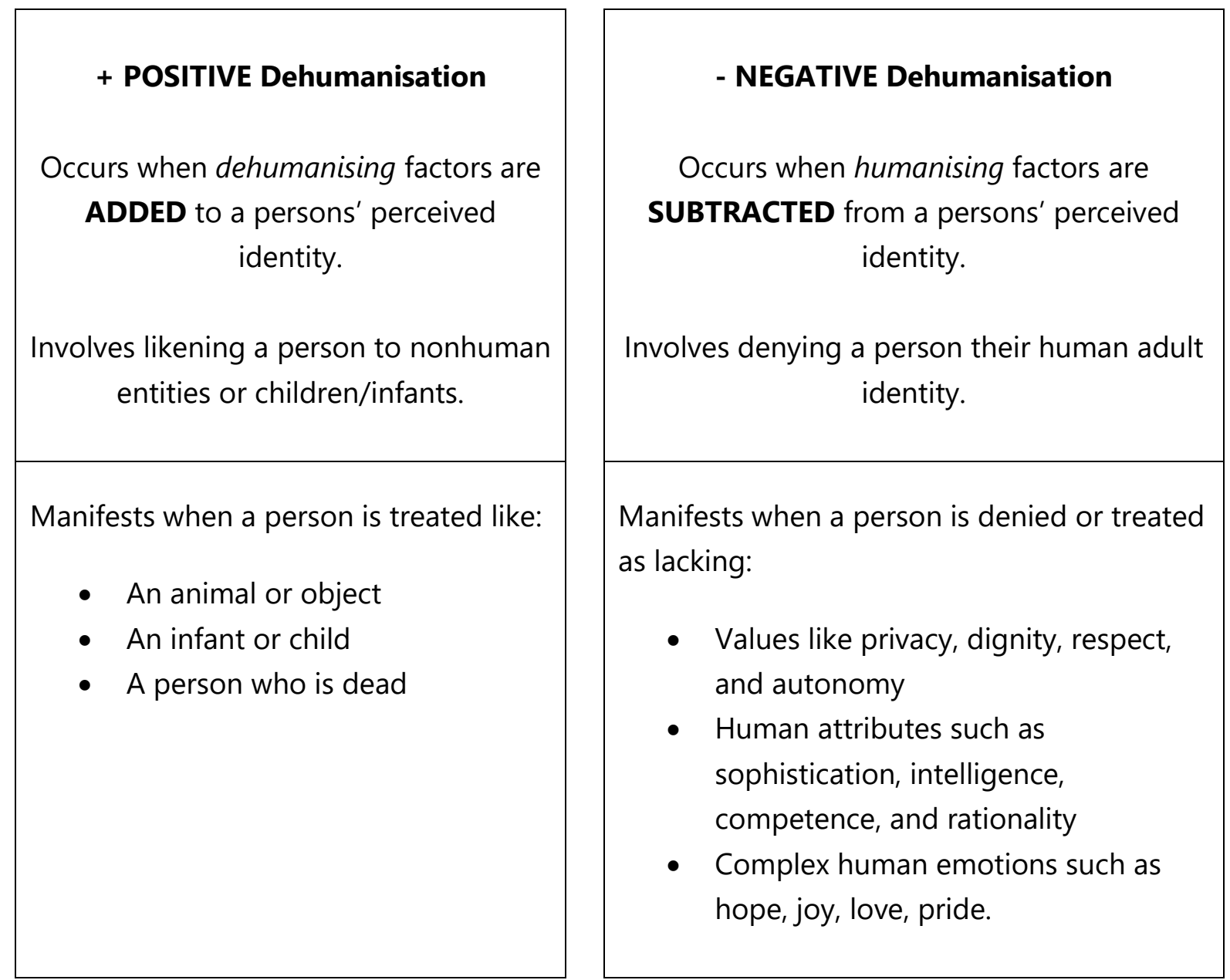

Figure 1. The New Model summarising positive and negative dehumanisation.

Note that these two forms of dehumanisation are not mutually exclusive as a person can be subjected to both forms of dehumanisation at the same time. For example, perceiving a person as lacking rationality would be classified as negative dehumanisation, whereas perceiving a person as irrational like an animal or child would be positive dehumanisation when in fact, lacking rationality and being irrational are the same. Also note that the model does not imply any directionality, as dehumanising perceptions may not necessarily precede a persons' dehumanising actions. Behavioural research has shown that a persons' attitude can be shaped by their behaviour - that is, the behaviour is performed first and then the attitude is formed to rationalise the behaviour after the fact (Albarracín and Wyer, 2000). The relationship between dehumanising thoughts and behaviours is likely bi-directional, but this represents an area for future research (Haslam and Loughnan, 2014). Despite these potential issues with the model, the model is still a useful starting point for explaining dehumanisation to students and workers in healthcare. 


\section{Construction of the model}

A variety of approaches have been taken in thinking about and framing dehumanisation, and the existing models and theories of dehumanisation in the literature were studied to construct the new model. Haslam's model (2006) describes dehumanisation as a violation of two dimensions of humanness - the first being characteristics that are uniquely human, and the second dimension being characteristics that describe human nature. Dehumanisation occurs when either of these are denied to a person or group. In this model, denying a person the first dimension of humanness - the uniquely human qualities that distinguish people from animals - constitutes animalistic dehumanisation and occurs when a person is perceived as lacking civility, refinement and self-restraint, self-control, or perceived as being immature and childlike (Haslam 2006). When the second dimension of humanness - human nature - is denied to a person, the person is treated like an object in what is termed mechanistic dehumanisation. The person is perceived superficially, as lacking emotional responsiveness or warmth or as being passive to their surroundings. They are considered as something inert, with little regard for their human mind or human needs.

The conceptual framework developed by Todres, Galvin, and Holloway (2009) describes 'humanisation' in contrast with dehumanisation. Eight dimensions of humanisation are identified in the framework that incorporates human values and describes what needs to be met for a person to feel like a full human being. The dimensions are agency, insiderness, uniqueness, togetherness, sense-making and personal journey, sense of place, and embodiment. In this framework dehumanisation is defined in terms of the fundamental human values that dehumanisers obscure; a person is dehumanised when any of the eight dimensions are violated. For example, violation of agency manifests as passivity where a person is held passive to their situation with diminished choices and control. Insiderness is violated when a person is objectified, and denying uniqueness results in homogenisation in which differences between people are not respected and the person is treated in same way as everyone else - 'oppressed by sameness, routine and repetitious activity' (Todres, Galvin, and Holloway, 2009). Violating togetherness causes isolation and denies the person basic human interaction and social life, such as the social exclusion people with dementia often face.

Kamfe (1990) states that autonomy, communication, privacy, and respect are necessary for human dignity, and that violations of these deny a person full human dignity and consequently dehumanise the person. Kamfe's work specifically explores dehumanisation in the context of aged care and identifies the violations that dehumanise people living in residential aged care facilities. Lack of autonomy refers to practices that diminish the persons agency, such as social exclusion by not allowing the person to participate in social interaction or lifelong habits. Exclusion can also mean not allowing the person to make decisions about their life, the care services they receive, and even daily activities like sleeping and hygiene routines. Communication problems addresses the need for a person to be spoken to, spoken about, and spoken around in a way that reflects the fact that they are a person. Kamfe describes lack of privacy as the many ways in which people living in aged care facilities are denied basic privacy. Examples include walking into the persons' private spaces without 
knocking or interrupting the person during private activities. Treated with or thought of with disrespect describes stereotyping, using the wrong name preference, assuming the person thinks unclearly because they are older, and ignoring the persons' preferences as some examples. The person is treated with less respect and not perceived to be competent or intelligent.

Similar to Kamfe, Berdes (1987) identifies three main 'themes of humanisation' that are central to personhood in the context of aged care: control, privacy, and relationships. Control and privacy highlight similar issues to Kamfe, but Berdes also includes relationships as a theme of humanisation to emphasise the importance of social life to being human. People are social beings and have a fundamental need to belong, evident by the 'severe negative consequences that occur when someone is socially excluded' (Galinsky, Wu and Kang, 2005). To deprive a person of social connection is therefore fundamentally dehumanising. Berdes also considers an earlier model of dehumanisation developed in the context of mental institutions that proposes four 'modes' of dehumanisation: '(1) person as trivium, an adult treated like a child; (2) person as inanimate object, particularly in a passive sense, in which one person becomes the product of another's work; (3) person as animal, that is, a lower or less sensible life-form; and (4) person as other, seen as a nonperson because of physical or mental damage' (Berdes, 1987: 373). This last example especially highlights the role of stereotyping as being a major contributor to dehumanisation.

When reviewing the literature on dehumanisation, two themes become apparent: some types of dehumanisation involve perceiving or treating a person as having animal-like, childlike, or object-like characteristics, and some types of dehumanisation involve perceiving or treating a person as lacking human and adult-like characteristics. This observation informed the separation of dehumanisation in the New Model into the two types - positive and negative. The various models and theories of dehumanisation share other commonalities important to the new model. Firstly, nearly all address both perceptions and behaviours. There are actions that can be taken towards a person to dehumanise them, while there are also thoughts, ideas and attitudes that dehumanise a person. To be inclusive of both these aspects of dehumanisation, the New Model uses the terms 'likened to' and 'denied'. For example, likening a person to an animal can involve both treating a person like an animal or simply thinking of the person as being like an animal, and denying a person respect can mean treating the person with a lack of respect or having disrespectful thoughts about the person. The model treats both thoughts and actions as important which is necessary given the strong link between the two as indicated by the previously mentioned literature. Furthermore, the models and theories on dehumanisation all describe how dehumanisation is generally a bad thing - they not only simply describe the phenomenon but explain why it is bad for people and societies. However, research has also considered how dehumanisation can serve a protective function, such as in healthcare where dehumanising patients has been found to be mental strategy to protect oneself against the consequences of caring for people who are suffering - for example, to prevent burnout, emotional stress, and psychological trauma (Vaes and Muratore, 2013). Despite this possible role for protection, dehumanisation as a strategy is potentially maladaptive and has poor 
outcomes for the well-being of the people dehumanised (Haque and Waytz, 2012). Thus, dehumanisation is overwhelmingly framed in the literature as a problem, and the New Model expresses this accordingly by characterising the different aspects of the problem.

In summary, the New Model presents a new way of describing dehumanisation that has been synthesised from current understanding about the phenomenon and reflects what is presently known about the subject. The model is simplified and may not provide full coverage of dehumanisation given how complex the phenomenon is, but nonetheless presents an overview of dehumanisation adequate for training and education purposes in healthcare.

\section{The New Model in Training and Education in Dementia Care}

Dehumanisation of people with dementia living in aged care facilities is a major problem in Australia and the new model was developed in the context of finding training and education solutions for addressing the problem. The new model aims to summarise existing theories and models of dehumanisation into one model that can be understood by people with all kinds of backgrounds and levels of education, which is important given that a large portion of the aged care workforce in Australia have very basic levels of education, training, and English-speaking ability (Royal Commission into Aged Care Quality and Safety, 2019). Ideally, the new model makes dehumanisation theory accessible to students and trainees in healthcare, care workers/personal carers, nurses, doctors, allied health staff, volunteers and other paid and unpaid people involved in dementia care. It has the potential to reduce dehumanisation in dementia care by being incorporated into training material that can be used to teach these groups how to identify and avoid dehumanisation. For example, when considering if one person is being dehumanised by another, training could help staff and students ask: is the person being treated like an animal, child, or object? If the answer is yes, then positive dehumanisation is occurring. For negative dehumanisation, the question is: is the person being denied their adult identity? The New Model has not yet been tested but offers potential utility in developing training resources targeted to reducing dehumanisation in aged care.

\section{Other Applications}

The New Model is widely applicable to topics beyond dementia care as this section will briefly illustrate. The model can be useful for understanding dehumanisation in contexts such as ageism, racism, and politics. For starters, older people are often dehumanised. For example, consider stereotypes that characterise older people as being frail, senile, lonely, and lacking independence (Dionigi, 2015). Such stereotyping is a form of negative dehumanisation because the older person is painted as lacking human attributes like sophistication, intelligence, and competence. When considering racism through the lens of the New Model, positive dehumanisation is widespread in the dehumanisation of ethnic groups. Research has explored how African Americans have historically been described as excessively violent or irrational, likening these people to brutes or savage animals (Haslam, 2006; Mekawi, Bresin and Hunter, 2019). Even today such dehumanising perceptions 
engender greater support for violence and severe punitive measures against African American people (Mekawi, Bresin and Hunter, 2019). Ascribing animal-like qualities to people classifies this as a form of positive dehumanisation under the New Model. The model is also relevant for politics. For example, in 2020 US president Donald Trump used dehumanisation as an election campaign strategy to reduce support for his opponent, Joe Biden, by arguing that Biden was losing his cognitive ability and becoming incompetent. By doing so, Trump was suggesting that Biden lacked an adult identity by denying him these key human attributes and consequently dehumanised him in what the New Model terms negative dehumanisation. These examples show that the model can be useful for understanding dehumanisation in a variety of important contexts.

There are numerous aspects of dehumanisation that are not yet fully understood and represent areas for future research, but despite these knowledge gaps the New Model has potential for being a tool with high utility in training and educations programs for reducing dehumanisation in dementia care and other settings.

Notes: these authors agree that the term dementia is outdated and support the use of the term major neurocognitive disorder, as defined by the DSM-5. However, the term dementia was used in this paper to help make the content of the paper more accessible to healthcare workers and other readers who are more familiar with the term dementia.

\section{References}

Albarracín, D. and Wyer, R. S, (2000), 'The Cognitive Impact of Past Behavior: Influences on Beliefs, Attitudes, and Future Behavioral Decisions', Journal of Personality and Social Psychology, 79 (1), 5-22 Berdes, C. (1987), 'The Modest Proposal Nursing Home: Dehumanizing Characteristics of Nursing Homes in of Nursing Home Residents', Journal of Applied Gerontology, 6 (4), 372-388

Boddington, P. and Featherstone, K. (2018), 'The canary in the coal mine: Continence care for people with dementia in acute hospital wards as a crisis of dehumanization', Bioethics, 32 (4), 251-260

Borbasi, S., Galvin, K. T., Adams T., Todres, L. and Farrelly, B. (2012), 'Demonstration of the usefulness of a theoretical framework for humanising care with reference to a residential aged care service in Australia', Journal of Clinical Nursing, 22, 881-889

Brannelly, T. (2011), 'Sustaining citizenship: People with dementia and the phenomenon of social death', Nursing Ethics, 18 (5) 662-671

Dionigi, R. (2015), 'Stereotypes of Aging: Their Effects on the Health of Older Adults', Journal of Geriatrics, 2015, 1-9

Galinsky, A., Gillian, K. and Wang, C. (2005), 'Perspective-Taking and Self-Other Overlap: Fostering Social Bonds and Facilitating Social Coordination', Group Processes \& Intergroup Relations, 8 (2), 109124 
Haque, O. S. and Waytz, A. (2012), 'Dehumanization in Medicine: Causes, Solutions, and Functions', Perspectives on Psychological Science, 7 (2), $176-186$

Haslam, N. (2006), 'Dehumanization: An Integrative Review', Personality and Social Psychology Review, 10 (3), 252-264

Haslam, N. and Loughnan, S. (2014), 'Dehumanization and Infrahumanization', Annual Review of Psychology, 65 (1), 399-423

Haslam, N. and Stratemeyer, M. (2016), 'Recent research on dehumanization', Current Opinion in Psychology, 11, 25-29

Heap, C. and Wolverson, E. (2018), 'Intensive Interaction and discourses of personhood: A focus group study with dementia caregivers', Dementia, 19 (6), 2018-2037

Mekawi, Y., Bresin, K., and Hunter, C. (2019) 'Dehumanization of African-Americans Influences Racial Shooter Biases', Race and Social Problems, 11, 299-307

Miron, A. M., Mcfadden, S. H., Nazario, A. S. and Buelow, J. (2017), 'Perspective taking, empathic concern, and perceived humanness of people with dementia', Educational Gerontology, 43 (9), 468-479

Persson, T. and Wästerfors, D. (2009), "'Such Trivial Matters:" How staff account for restrictions of residents' influence in nursing homes', Journal of Aging Studies, 23, 1-11

Seaman, A. (2020), '"Like He's a Kid": Relationality, Family Caregiving, and Alzheimer's Disease', Medical Anthropology, 39 (1), 29-40

Royal Commission into Aged Care Quality and Safety (2019) 'Interim Report - Volume 1' published 31 October 2019

Ryvicker, M. (2009), 'Preservation of self in the nursing home: Contradictory practices within two models of care', Journal of Aging Studies, 23, 12-23

Speering, H, Speering, L, and Archer, H (2020) 'Dehumanising Language in Dementia Care Settings', International Dementia Conference, Sydney, Australia, 21-22 September, 2020.

Swaffer, K. (2014), 'Dementia: Stigma, Language, and Dementia-friendly', Dementia, 13 (6), 709-716

Todres, L., Galvin, K. T. and Holloway, I. (2009), 'The humanization of healthcare: A value

framework for qualitative research', International Journal of Qualitative Studies

on Health and Well-being, 4 (2), 68-77

Vaes, J. and Muratore, M. (2013), 'Defensive dehumanization in the medical practice: A cross-sectional study from a health care worker's perspective', British Journal of Social Psychology, 52, 180-190 